
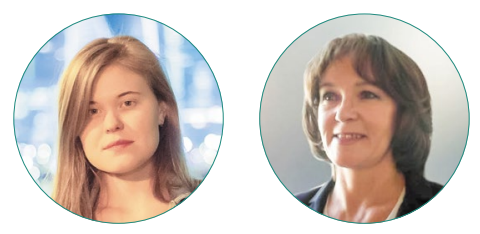

К. В. Попкова, Е. С. Балабанова

\title{
МОТИВАЦИЯ ТРУДА ТВОРЧЕСКИХ РАБОТНИКОВ: НОРМАТИВНЫЕ ПРЕДСТАВЛЕНИЯ И РЕАЛЬНОСТЬ ТРУДОВОЙ ЖИЗНИ
}

\section{Правильная ссылка на статью:}

Попкова К.В., Балабанова Е.С. Мотивация труда творческих работников: нормативные представления и реальность трудовой жизни // Мониторинг общественного мнения: экономические и социальные перемены. 2021. № 3. С. 290-315. https://doi.org/10.14515/ monitoring.2021.3.1884.

\section{For citation:}

Popkova K. V., Balabanova E.S. (2021) Labor Motivation of Creative Professionals: Normative Vision and the Reality of Working Life. Monitoring of Public Opinion: Economic and Social Changes. No. 3. P. 290-315. https://doi.org/10.14515/monitoring.2021.3.1884. (In Russ.) 
МОТИВАЦИЯ ТРУДА ТВОРЧЕСКИХ РАБОТНИКОВ: НОРМАТИВНЫЕ ПРЕДСТАВЛЕНИЯ И РЕАЛЬНОСТЬ ТРУДОВОЙ ЖИЗНИ

ПОПКОВА Кристина Владимировна руководитель проектов, Online Market Intelligence, Москва, Россия

E-MAIL: kristina-popkova-1996@mail.ru https://orcid.org/0000-0000-0000-0000

БАЛАБАНОВА Евгения Сергеевна - доктор социологических наук, профессор департамента социологии, Национальный исследовательский университет "Высшая школа экономики", Москва, Россия

E-MAIL: balabanova@hse.ru

https://orcid.org/0000-0003-2007-1773

Аннотация. Статья посвящена проблеме изучения специфики организации труда и влияния организационных управленческих практик на работников творческих профессий в условиях российского контекста.

Эмпирическая часть исследования основана на анализе данных, полученных в 2019-2020 гг. в ходе реализации двух этапов стратегии "последовательных вкладов" (mixed methods research) - глубинных интервью $(N=23)$ и стандартизованного онлайн-опроса $(N=302)$.

Один из важнейших результатов исследования - выявление противоречий между нормативным дискурсом, связанным со спецификой труда творческих работников, и результатами количественного этапа исследования. Приоритетность "содержательных" аспектов работы, автономии и возможностей самореализации для мо-
LABOR MOTIVATION OF CREATIVE PROFESSIONALS: NORMATIVE VISION AND THE REALITY OF WORKING LIFE

Kristina V. POPKOVA ${ }^{1}$ — Project Manager E-MAIL: kristina-popkova-1996@mail.ru https://orcid.org/0000-0000-0000-0000

Evgeniya S. BALABANOVA ${ }^{2}$-Dr. Sci. (Soc.), Professor of the Department of Sociology E-MAIL: balabanova@hse.ru https://orcid.org/0000-0003-2007-1773

\footnotetext{
${ }^{1} \mathrm{OMI}$ (Online Market Intelligence), Moscow, Russia

2 HSE University, Moscow, Russia
}

Abstract. The article is aimed to study the specifics of work organization and the impact of organizational management practices on creative professionals in the Russian context. The study was carried out in the mixed methods methodology and is based on empirical data collected in 2019-2020 through in-depth interviews $(N=23)$ and a standardized online survey $(N=302)$. The article reveals a contradiction between the normative discourse associated with the specifics of the work of creative professionals and the results of the quantitative stage of the research. In in-depth interviews, the informants emphasized the priority of "substantive" aspects of work, autonomy and self-realization opportunities for motivating creative output. However, this was not supported by a mass survey. Regression analysis showed that aspects related to the satisfaction of material needs and perceived fairness in salary are significant for satisfaction with the work of creative professionals, their ex- 
тивации творческого труда, подчеркиваемая информантами в углубленных интервью, не получила подтверждения в массовом стандартизованном опросе. Результаты регрессионного анализа показали, что ведущую роль для удовлетворенности трудом творческих работников, их надролевого поведения, вовлеченности, эмоционального выгорания, намерений сменить работу играли аспекты, связанные с удовлетворением материальных потребностей и воспринимаемой справедливостью в оплате труда. Факторы же самореализации и автономии в большинстве моделей оказались незначимыми.

При этом результаты исследования подтверждают ранее выявленную в литературе и отраженную в глубинных интервью исключительно высокую значимость фактора групповых взаимодействий, командной работы. Обнаружено также достаточно терпимое отношение к конфликтам в трудовом процессе, что, на взгляд авторов, отражает специфику творческого труда.

Кроме того, было показано, что установки и поведение творческого работника обусловлены прежде всего организационно-управленческими факторами, а не социально-демографическими или индивидуальноличностными особенностями.

Ключевые слова: творческая отрасль, творческая профессия, профессиональная идентичность, мотивация труда, удовлетворенность работой, вовлеченность в работу, надролевое поведение, профессиональное выгорание, конфликты tra-role behavior, involvement, emotional burnout, and intentions to change jobs. Factors of self-realization and autonomy turned out to be insignificant in most of the models. The results of the study confirm the extremely high importance of the factor of group interactions and teamwork, previously identified in the literature and reflected in the in-depth interviews. The research results also show the respondents' tolerant attitude to conflicts in the labor process, which, in the authors' opinion, reflects the specifics of creative work. The article concludes that the attitudes and behavior of a creative professional are primarily determined by organizational and managerial factors, but not socio-demographic or individual characteristics.

Keywords: creative industry, creative profession, professional identity, work motivation, job satisfaction, work engagement, extra-role behavior, professional burnout, conflicts 


\section{Введение}

Современная среда развития творческих отраслей стремится к снижению неопределенности в отношении потенциального успеха у потребителя, что свойственно созданию культурного блага, ориентирующегося на запросы рынка и учет динамики его изменений. Обозначенный ситуативный контекст способствует формированию условий для системы управления и организации труда, где творческие личности одновременно соответствуют как художественной, так и коммерческой логикам культурного производства [Duran, Jourdan, 2012: 1298].

На институциональном уровне отрасли в сфере культуры, искусства и творчества в России развиваются в русле описанных тенденций. Как свидетельствуют результаты исследований, представители творческих профессий сталкиваются с высоким уровнем конкуренции на рынке труда, что формирует определенный перечень барьеров при трудоустройстве ${ }^{1}$. Потенциальным кандидатам, претендующим на позицию в сферах с высокой конкуренцией, необходимо регулярно повышать профессиональный уровень, изучать смежные профессии, развивать soft skills, чтобы быть востребованными на рынке труда².

Сложность и специфику труда творческих работников определяет следующее: отрасли, связанные с культурой, искусством и творчеством в основе своей деятельности содержат элементы духовного, а не материального производства, однако тенденции современности стремительно определяют данную особую область социально-трудовых практик как соответствующую логике экономической целесообразности. Это формирует противоречивое поле осуществления трудовой деятельности, в рамках которого мотивация труда работников имеет творческий характер и зависит не только от индивидуальных способностей и таланта, но и от специфических актуальных знаний работы отраслевого рыночного механизма. Оценка и стимулирование производительности, мотивации трудовой деятельности, применение моделей и механизмов воздействия тесно переплетаются с наличием условий для реализации творческого потенциала, формированием внутриорганизационной (профессиональной) идентичности в процессе командной (проектной) или индивидуальной работы в творческом коллективе.

Выдвинутые аргументы актуализируют проблему изучения специфики и влияния системы организационного управления на мотивацию труда работников творческих профессии в условиях российского контекста, а также фокусируют научно-исследовательский интерес вокруг решения вопроса, как взаимодействуют "эстетическая" и "рыночная" логики в системе мотивации труда творческих работников.

\section{Теоретические подходы к анализу труда творческих работников}

Отправной точкой нашего анализа выступает осмысление основных понятий и характерных особенностей занятости представителей данной профессиональной группы в рамках научного дискурса.

\footnotetext{
${ }^{1}$ Соколов Н. Названы профессии с высокой конкуренцией на рынке труда //RT. 2019. 25 ноября. URL: https:// russian.rt.com/russia/news/689481-professii-vysokaya-konkurenciya-rynok (дата обращения: 20.03.2020).

2 Основные тенденции на рынке труда в России // HeadHunter. 2018. 7 мая. URL: https://hh.ru/article/22393 (дата обращения: 25.03.2020).
} 
Для анализа объекта исследования основополагающее значение имеет определение критериев принадлежности к "культурным", или “креативным", отраслям, концептуализация которых в ряде работ позволяет использовать термины cultural (культурная) и creative (креативная, творческая) в качестве взаимозаменяемых [Peterson, Anand, 2004: 316]. Культурная индустрия - это сфера производства продукта творческого труда, нацеленного на потребительский рынок [Peltoniemi, 2014]. Именно производство творческого продукта как конечного предмета потребления является тем, что отличает творческие профессии и отрасли от других видов деятельности, также включающих элементы творчества, но продукты которых являются "промежуточным" этапом некой конечной цели - например, основой для принятия управленческих или инвестиционных решений (научные исследования, аналитика, консультирование) или средством стимулирования сбыта (реклама).

Существует определенный консенсус, что к "творческим" относятся кинематографическая, музыкальная отрасли, издательское дело, театр и опера, телевидение, радио и изобразительное искусство [Cowen, 2000]. Другие авторы предлагают более широкий перечень отраслей, добавляя к вышеупомянутым архитектурную, дизайнерскую деятельность, новые медиа, отрасли видеоигр, фотографии [Hesmondhalgh, 2002]. Традиционные секторы культуры и искусства, деятельность которых направлена на сохранение культурного наследия, исполнительское искусство, также включены в указанную классификацию [Матецкая, 2011: 196].

В рамках настоящего исследования авторское понятие "творческая профессия" опирается на трактовку профессиональной деятельности по Э. Хьюзу [см. Романов, Ярская-Смирнова, 2015]: это вид трудовой деятельности, направленный на создание уникального продукта творческого труда. Определение "творческий работник", согласно принятой в 1980 г. ЮНЕСКО рекомендации “О положении творческих работников", подразумевает любое лицо, которое создает или интерпретирует произведения искусства, участвуя тем самым в их воссоздании. Данное понятие зафиксировано в ряде международных правовых актов (Всемирной конвенции об авторском праве, Бернской конвенции об охране произведений литературы и искусства, Римской конвенции об охране прав артистов - исполнителей, производителей фонограмм и работников органов радиовещания) а также в "Основах законодательства РФ о культуре " ${ }^{3}$.

Вопрос о принципиальных отличиях "творческого" труда от "нетворческого" остается дискуссионным в научной литературе [Throsby, 2001; Peltoniemi, 2014]. С одной стороны, широко признано наличие уникальной профессиональной идентичности представителя творческого труда. Это отражено в понятии «поле искусства", которое П. Бурдье интерпретировал как социальный универсум производителей (художественных) произведений [Бурдье, 2001: 50]. Важная особенность поля искусства заключается в том, что личностное и профессиональное в творчестве художника практически неразделимы [Магидович, 2004: 141]. Как подчеркивают многие авторы, творческий труд настолько специфичен, что требует

\footnotetext{
3 Международные нормативные акты ЮНЕСКО //Консультант Плюс. URL: http://www.consultant.ru/cons/cgi/online. cgi?req=doc\&base=INT\&n (дата обращения: 07.03.2020).
} 
системы организации, мотивации работы, принципиально отличной от других видов деятельности, о чем речь пойдет ниже.

С другой стороны, все чаще подвергается сомнению уникальность творческих отраслей и профессий и "монополия" последних на творчество в профессиональной деятельности. Указывается, что креативность как личностное качество и навык сегодня востребована в самом широком спектре профессий и отраслей [Amabile, Pratt, 2016]. Наблюдается и встречный процесс: подвергается "эрозии" сам процесс культурного производства. Художник (в широком смысле) все сильнее вынужден ориентироваться на запросы массовой аудитории, учитывать коммерческую окупаемость своих проектов. Характеристики творческого труда оказываются пронизаны прежде не свойственной им дистрибутивно-ориентированной деятельностью. Социологическая интерпретация подобного явления находит свое отражение в работах представителей критического направления [Адорно, Хоркхаймер, 1997] и в концепции "культуриндустрии", рассматривающейся в качестве синонима массовой культуры. Культура перестает выполнять критическую функцию и быть ценностным мерилом, превращается в производственный процесс, в товар, вещь [Peterson, Anand, 2004].

По нашему мнению, указанные противоречия удовлетворительно разрешаются в рамках концепции "институциональных логик" как совокупности материальных практик и символических конструкций, создающих принципы организации поля и способных достраиваться коллективными и индивидуальными факторами [Скотт, 2007]. В процесс создания творческого продукта активно включаются принципы и процедуры, свойственные иным видам деятельности, что, однако, не отменяет базового критерия определения творческой профессии или отрасли - производства культурных ценностей как конечного продукта.

Именно концепция институциональных логик представляется наиболее продуктивным теоретическим конструктом для анализа мотивации труда творческого работника в рамках организационных границ, формирования ценностей и убеждений, которые лежат в основе целей и стратегий управления в организации. Институциональные факторы внутри организации - это индивиды, выполняющие определенные роли, организации или ассоциации, деятельность которых направлена на создание и реализацию институциональных логик; системы управления включают механизмы, поддерживающие формальные схемы контроля [Скотт, 2007]. Личностные и профессиональные установки закладываются в основу материальных практик и обусловливают различия между социальными порядками, существующими в одной и той же сфере деятельности [Панов, 2018: 138].

\section{Что мотивирует работников творческих профессий и отраслей? Обзор результатов исследований}

Фокусируясь на теоретическом осмыслении мотивационной структуры, важно отметить, что природа труда порождается в том числе и новым духом капитализма, о котором писали Л. Болтански и Э. Кьяпелло [Boltanski, Chiapello, 2005: 115]. Изменения, соответствующие данной концепции, предполагают, что труд, работа и профессиональная деятельность направлены на удовлетворение запросов потребителя, которые реализуются внутри коллективов, образующихся в рамках 
конкретного проекта. Это способствует формированию системы гибкого планирования, стратегии изменения организации труда внутри компаний в рамках Agile-подхода. Ярким примером служит появление на рынке услуг и различных платформ по подбору творческих проектных команд для решения задач исходя из потребностей конкретного заказчика/аудитории.

У работников креативных отраслей формируется двойственная идентичность “эстетическая" и “эффективная" [Thornton, Jones, Kury, 2005]. Двойственная природа формирования идентичности творческого работника создает поле управленческих практик, в рамках которого организация вынуждена адаптироваться под специфику и противоречия, возникающие у представителей творческого труда внутри организационных границ.

Так, результаты эмпирического исследования работников архитектурной отрасли описывают формирование двух гибридных логик: эстетической и эффективной. В рамках первой профессиональной группе свойственно объединение творческих интересов профессии с целями, диктуемыми организацией и рынком в целом. Приоритет остается за художественной эстетикой, в то время как особое внимание отводится мастерству и навыкам продаж услуги дизайнеров внутри компании. Это формирует у работника идентичность “художника-предпринимателя". Вторая логика объединяет в себе вопросы безопасности и полезности, от которых напрямую зависит деятельность компании. На профессиональную идентичность архитектора влияет результат решений технологических задач и практическая польза конечного продукта [ibid.: 130]. В совокупности творческие идеи должны вводить новшества в управляемых пределах, поскольку производство интегрировано в экономический контекст, где искусство и бизнес тесно переплетены [Eikhof, Haunschild, 2006: 237].

В работе британских и американских исследователей [Gotsi et al., 2010: 791] выделяются два подхода к регулированию последствий, связанных с напряженностью по отношению к идентичности, с которой сталкиваются работники творческого труда: стратегия дифференциации и стратегия интеграции. Рассматриваемые противоречия формируются на основе того, что данная категория трудового коллектива, с одной стороны, целью своей деятельности видит самовыражение, реализацию творческого начала как источника инновационного потенциала, а с другой - подвержена ежедневному давлению, заключающемуся в наличии сроков выполнения контракта, требований, диктуемых рынком. Это способствует развитию деловой идентичности внутри организации, которая призвана поддерживать работу компании. Логика анализа и реализации на уровне внедрения организационных практик в компаниях обосновывала применение третьей стратегии смешения, которая призвана обеспечивать формирование системы, где идентичности работника сохраняют индивидуальную, творческую направленность, но в то же время структурируются в соответствии с организационными целями и ожиданиями (метаидентичность).

Специфика дифференциации и расслоения внутри творческого коллектива (а также распределение власти внутри креативных индустрий) является одним из неотемлемых аспектов формирования среды организационного управления и мотивации труда. Неравенство в коллективе может быть связано с реализацией 
принципа "winner takes all" ("победитель забирает все»): существующие ресурсы (финансовые, ресурсы признания) неравно распределяются между большинством работников и несколькими "звездами" [Кулева, 2017: 56]. Кроме того, при декларируемой открытости, разнообразии и автономии работы в креативных отраслях наблюдаются "масштабные и устойчивые» неравенства, основанные, в частности, на гендерных различиях [Conor, Gill, Taylor, 2015: 12].

Работникам творческого труда в организации требуется значительная автономия из-за необходимости в оригинальности и новизне при создании конечного продукта [Hesmondhalgh, 2002]. Эмпирические результаты, подтверждающие это, выдвигают ряд ограничений для творческого работника, которые связаны с увеличением масштаба проекта, повышением сложности его структуры [Tschang, 2007: 990]. Менеджеры в организациях могут как перенаправлять, так и блокировать творческую деятельность, оказывать влияние на мотивационную составляющую труда. Инструментами таких воздействий являются ограничение свободы действий и увольнение работников, которые не соответствуют внутренним стандартам и требованиям. Перечень показателей, определяющих эффективность работы, индивидуален для каждой отрасли и даже организации, таким образом, четко не регламентирован и не закреплен, что, в свою очередь, создает ситуацию неопределенности для работника и может причиной низкой приверженности к данной организации. Благоприятную среду для проявления работником своих креативных способностей создает заинтересованность в своих проектов, обладание высоким уровнем автономии и контроля над выполнением индивидуальной работы, наличие необходимых ресурсов для осуществления деятельности, а также высокий уровень интеллектуальной сложности труда [Ensor, Cottam, Band, 2001].

Значимость для мотивации персонала системы организации труда, содержательных характеристик работы (core job characteristics) и условий работы (job design) - давно признанный факт в социологии управления и исследованиях организаций [Hackman, Oldham, 1980]. Опираясь на теорию самодетерминации [Deci, Olafsen, Ryan, 2017], исследователи в области мотивации труда подчеркивают, что важнейшей задачей в области управления персоналом является выстраивание системы стимулирования, вознаграждений, условий, которые бы позволяли поддерживать высокий уровень "внутренней" (intrinsic) мотивации труда, связанной с содержанием, смыслом работы [Cerasoli, Nicklin, Ford, 2014]. О правильно выстроенной системе мотивации свидетельствует результативность, или эффективность, труда - которая может быть измерена как выполнением конкретных задач (task performance), так и выраженностью позитивных эмоций, установок в отношении работы и организации, демонстрацией желательного для организации поведения (contextual performance) [Wright, Staw, 1999; Harrison, Newman, Roth, 2006]. Поскольку показатели первой группы уникальны для каждой отрасли, профессии или организации, то в смешанных выборках, как правило, используются именно составляющие "контекстуальной эффективности", такие как удовлетворенность работой, вовлеченность в работу (work engagement), желание остаться в организации, надролевое поведение, отсутствие эмоционального выгорания. Испытывая позитивные установки по отношению к своей работе и организации, работники вкладывают личностные, профессиональные ресурсы 
в исполнение рабочих задач, поэтому, к примеру, феномен вовлеченности в работу с полным правом считается мотивационной переменной [Kahn, 1990; Rich, LePine, Crawford, 2010; Schaufeli et al., 2002]. Таким образом, в эмпирическом исследовании, представленном ниже, мы определяем выраженность мотивации творческих работников через их позитивные установки и надролевое поведение.

Итак, на основе проведенного анализа было определено проблемное поле нашего исследования.

1. Теоретическая проблема основана на отсутствии в научной литературе теоретического анализа с его последующим эмпирическим обоснованием мотивации труда творческих работников в России, чей потенциал и навыки в современной экономике носят всеобъемлющий и непрерывный характер, а креативность в экономических и технологических областях имеет прямую зависимость от проявлений и развития сферы художественного творчества и культуры [Флорида, 2016: 25].

2. Эмпирическая проблема заключается в отсутствии разработанного исследовательского инструментария, уход от комплексного анализа в пользу использования исключительно качественных методов, что препятствует созданию среза актуальной информации о специфике организации труда, формирующей мотивационную структуру данной профессиональной группы. В качестве объекта исследования в большинстве работ анализируются потребители творческого продукта (аудитория), а не работник творческого труда.

\section{Нормативные ожидания творческих работников: результаты глубинных интервью}

В основе изучения мотивации труда творческих работников лежит методология исследования, которая соответствует специфике проведения mixed methods research, а именно реализации стратегии «последовательных вкладов" (типология Д. Моргана), и включает два этапа: сбор качественных данных (метод глубинного интервью) и сбор количественных данных (метод анкетного онлайн-опроса).

Стратегия подразумевает сбор качественных данных, анализ которых позволяет задать вектор реализации основного количественного метода, сгенерировать гипотезы, разработать вопросы для анкеты, шкалы, способствует пониманию сенситивных моментов и поиску новых социальных феноменов [Савинская и др., 2016: 26]. Решение подкреплено потребностью в концентрации внимания на частном, специфическом социальном опыте информантов, выявлении необходимых аспектов для формирования количественного инструментария и уточнения системного описания объекта исследования [Квале, 2003: 23].

Информанты для проведения глубинных интервью отбирались с учетом равного распределения по половозрастной структуре, региональной и профессиональной принадлежности. В список информантов вошли работники театральной и архитектурно-дизайнерской отраслей в Москве и Новосибирске $(N=23)$. Условием отбора информантов была их принадлежность к "творческим профессиям" в соответствии с упомянутой выше отличительной особенностью творческого труда - созданием конечного специфического творческого продукта, творческой деятельностью как основной, в отличие от административной, инженерной, технически-вспомогательной. Таким образом, в качестве информантов для 
проведения качественного этапа были отобраны представители театральной и архитектурно-дизайнерской отраслей: актеры, режиссеры, художественные руководители, архитекторы и дизайнеры. Обозначенная логика отбора информантов позволила исключить так называемую нетворческую часть работников организации, которые вносят вклад в процессы создания специфического творческого продукта (например, технический персонал оперных и театральных трупп, персонал зрительного зала, уборщики, бухгалтеры, экскурсоводы, литературные агенты и др.) [Throsby, 2001].

Отвечая на поставленный исследовательский вопрос, мы фокусируемся на специфике управления внутри выбранных творческих отраслей и влияния на мотивацию труда данной профессиональной группы. Результаты анализа позволили сформулировать ряд основных выводов.

1. Специфика рассматриваемых профессий заключается в особом подходе к управлению творческим коллективом. Это проявляется как в критериях отбора сотрудников, так и в распределении обязанностей (ролей), где основополагающим оказывается субъективный фактор оценки способностей, потенциала работника.

...Всегда каким-то волюнтаристским способом решались эти проблемы, потому что либо режиссер, либо художественный руководитель, либо дирижер говорили, кто достоин, чтобы петь и играть, а кто не достоин, потому что не делает это так хорошо, как коллеги. (Информант № 1: художественный руководитель театра, 66 лет, Новосибирск)

2. Субъективность в оценке результата труда прослеживается на протяжении всей трудовой деятельности творческого работника. Влияние руководителя находит свое отражение в оценке профессиональных качеств, возможностей работника, в том числе на формирование условий занятости вне организации, которая в большинстве случаев неприемлема.

Да, конечно, мы можем уйти в другие проекты, но с начальником нужно это согласовать. (Информант № 5: актер театра, 29 лет, Новосибирск)

Да, у нас у каждого есть свои проекты, они нам направляются от руководителя. Запросы распределяются между дизайнерами, которые их в дальнейшем ведут. (Информант № 23: архитектор, 28 лет, Москва)

3. Трудовой договор является официальным документом, в котором соблюдение ряда положений имеет формальный характер. В частности, график работы. Работа в условиях гибкого графика (flexible working arrangements) позволяет сотрудникам формировать собственное расписание, которое соответствует их личным потребностям.

У нас нет такого, что нужно прийти в 11, а уехать в 8. Если утром репетиция, ты приезжаешь к одиннадцати часам на репетицию, если вечером нет спектакля, то ты свободен. Каждый понедельник выходной. Это прописано в договоре нашем. (Информант № 15: артист труппы, 59 лет, Москва) 
Контракты и договоры действительно есть, допустим, мы договариваемся, что работаем шесть дней. Но мы знаем, что даже если мы задержимся, то у нас есть дни, где мы не работаем, но они числятся как рабочие. Потому что театр так существует. (Информант № 13: ассистент режиссера, 44 года, Москва)

Я тебе скажу, что у меня не пятидневка: можно сказать - два через два, но бывает, что всего один выходной, и остальные - рабочие. Это могут быть рабочие дни как в офисе, так и дома. (Информант № 21: дизайнер интерьеров, 42 года, Москва)

4. Трудовая деятельность и личная жизнь тесно переплетены друг с другом. Отсутствие четкого графика работы, несмотря на наличие данного пункта в трудовом договоре, характеризует его как ненормированный. Творческие работники, склонны связывать жизнь и быт с представителями своего профессионального круга, так как это облегчает взаимопонимание и коммуникацию относительно специфики профессиональной принадлежности и решения личных вопросов. Для представителей архитектурно-дизайнерской отрасли данной зависимости выявлено не было.

Лично у меня: мы живем с двумя актерами еще вместе на служебной квартире. (Информант № 5: актер театра, 19 лет, Новосибирск)

В итоге все равно складывается, что у тебя весь круг общения так или иначе состоит из тех, кто работает в театре. У меня практически нет друзей, которые театра не касаются... Мы другой жизни не знаем, привыкли, находим свои плюсы. (Информант № 6: актер театра, 32 года, Новосибирск)

5. Формирование метаидентичности "художника-предпринимателя" - системы, в которой идентичность работника сохраняет индивидуальную, творческую направленность, но в то же время структурируется в соответствии с организационными целями и ожиданиями [Gotsi et al., 2010], в большей степени свойственно представителям архитектурно-дизайнерской отрасли и менее выражено у работников театра. Это проявляется как во внутренней специфике (распределении обязанностей), так и вне организации, которая в сравнении с иной деятельностью начинает рассматриваться исключительно в качестве источника дохода. Здесь мы можем наблюдать активное столкновение нормативных представлений о современных формах творческого труда и реальности, которая формирует запрос на поиск альтернативных источников творческого самовыражения через различные формы, не связанные с основным местом работы.

У нас изначально не было прописано, что мы все дизайнеры. Это стало проходить с ростом компании, когда она уже поняла, что может делать проекты большие, и тогда им понадобились дизайнеры. (Информант № 20: дизайнер интерьеров, 44 года, Москва)

Судя по тому, что работа не является всей моей жизнью. Она у меня как заработок для чего-то, а вне работы у меня много творчества. (Информант № 21: дизайнер интерьеров, 42 года, Москва) 
6. Высокая значимость "просоциального" типа надролевого поведения, выражающегося в передаче специфических навыков и знаний от более опытных сотрудников. Такое поведение повышает общую мотивацию работы сотрудников за счет взаимопомощи, наставничества, передачи знаний, инициативности сотрудников, отсутствия конфликтов и расценивается как проявление надролевого поведения [Балабанова и др., 2017: 186].

Очень дружная труппа, мне кажется, что это заслуга старичков, которые составляют основу театра лет десять минимум. Они так позиционируют себя и всех настраивают на рабочий лад. То есть приходишь и смотришь в первую очередь, как они работают. Они приходят и пашут. И ты понимаешь - значит, надо пахать! (Информант № 5: актер театра, 29 лет, Новосибирск)

\section{Организационно-управленческие факторы мотивации труда творческих работников: результаты стандартизованного опроса}

Этап сбора количественных данных был реализован с помощью проведения онлайн-опроса. Цифровизация сферы социологических опросов позволила верифицировать данную методику в качестве приемлемой для проведения в том числе и массовых опросов населения, рекрутируя их конвенциональным образом и с учетом оптимизации материальных затрат [Абрамов, 2019: 85]. Целесообразность применения выбранного метода обусловлена потребностью опроса людей с конкретными характеристиками, принадлежащими к такому узкому профессиональному сообществу, как российские работники творческих отраслей и профессий.

Для проверки выводов качественного этапа исследования, возможности их распространения на другие творческие отрасли и профессии было решено расширить список отраслей для рекрутирования респондентов. “Творческие отрасли", согласно Общероссийскому классификатору видов экономической деятельности (ОКВЭД), относятся к разделу $\mathrm{R}$ - «деятельности в области культуры, спорта, организации досуга и развлечений". Выборочная совокупность строилась по типу неслучайной квотной выборки, в пропорциях, соответствующих общей численности работников в этой группе отраслей ${ }^{4}$. Как и для углубленных интервью, условием отбора респондентов была их принадлежность к "творческим", а не административным или техническим, видам деятельности. Вопрос-фильтр приглашал к участию только тех респондентов, для кого творческая деятельность является основной. Одним из условий целесообразного составления количественного инструментария для такого специфического объекта исследования является непрямолинейное построение фильтрующих вопросов: например, демонстрация списка обязанностей в случайном порядке, который ранее был структурирован по "творческому" и "нетворческому" содержанию труда. Подобная логика построения вопроса позволяла на первом этапе заполнения анкеты отобрать респондентов, соответствующих характеристикам объекта исследования. Финальную выборочную совокупность составили только те респонденты, которые подходили по всем скринирующим условиям.

\footnotetext{
${ }_{4}$ Российский статистический ежегодник 2019. Стат. сб. М. : Росстат, 2019.
} 
Общее число опрошенных составило 302 человека. Итоговое распределение респондентов по основным социально-демографическим признакам представлено в таблице 1.

Таблица 1. Основные параметры выборки исследования (N=302), \%

\begin{tabular}{|c|c|}
\hline Параметры выборки & $\%$ \\
\hline \multicolumn{2}{|l|}{ Пол } \\
\hline Мужской & 43 \\
\hline Женский & 57 \\
\hline \multicolumn{2}{|l|}{ Возраст } \\
\hline 18-24 лет & 22 \\
\hline 25-34 года & 26 \\
\hline 35-44 года & 25 \\
\hline 45-54 года & 17 \\
\hline $55+$ & 10 \\
\hline \multicolumn{2}{|l|}{ Образование } \\
\hline Среднее профессиональное и ниже & 38 \\
\hline Высшее (бакалавриат, магистратура, специалитет) & 55 \\
\hline Два и более высших образования, аспирантура, ученая степень & 7 \\
\hline \multicolumn{2}{|l|}{ Регион проживания } \\
\hline Москва & 29 \\
\hline Санкт-Петербург & 12 \\
\hline Областные центры в других регионах & 59 \\
\hline \multicolumn{2}{|l|}{ Работают в организациях: } \\
\hline Государственных & 47 \\
\hline Частных & 53 \\
\hline \multicolumn{2}{|l|}{ Отрасль занятости } \\
\hline Театральная сфера & 18 \\
\hline Архитектурно-дизайнерская отрасль & 18 \\
\hline Сфера кино и телевидения & 9 \\
\hline Издательское дело & 5 \\
\hline Музыкальная отрасль & 12 \\
\hline Изобразительное искусство & 12 \\
\hline Другие & 26 \\
\hline
\end{tabular}

Опираясь на результаты углубленных интервью относительно нормативных ожиданий творческих работников, мы составили список наиболее важных, с точки зрения респондентов, условий, необходимых для их профессиональной деятельности. Таблица 2 демонстрирует частоту упоминания этих требований. 
Таблица 2. Распределение ответов на вопрос “Какие условия для осуществления творческой деятельности на рабочем месте являются обязательными лично для Вас? Возможен выбор нескольких вариантов ответа", \%

\begin{tabular}{|l|c|}
\hline \multicolumn{1}{|c|}{ Варианты ответа } & $\%$ \\
\hline Возможность самостоятельно формулировать цели своей работы & 76 \\
\hline Близкое по духу окружение & 63 \\
\hline Наличие четких, понятных целей работы & 44 \\
\hline Помощь коллег & 41 \\
\hline Высокий уровень доверия со стороны коллег и руководства & 41 \\
\hline Возможность самостоятельно определять способы выполнения своей работы & 36 \\
\hline $\begin{array}{l}\text { Возможность самостоятельно определять график, последовательность выполнения } \\
\text { своих рабочих задач }\end{array}$ & 23 \\
\hline Отсутствие жесткого контроля со стороны руководства, коллег & 19 \\
\hline Приоритет коллективной работы над индивидуальной & 10 \\
\hline Приоритет индивидуальной работы над коллективной & 2 \\
\hline
\end{tabular}

Обратим внимание на отмеченную респондентами исключительно высокую значимость автономии в определении целей своей работы, что соответствует выводам зарубежных исследователей [Ensor, Cottam, Band, 2001; Hesmondhalgh, 2002; Tschang, 2007]. Даже притом, что выборка состояла из профессионалов, работающих по найму в организациях, значимость "содержательной" автономии, которую отметили три четверти опрошенных, значительно опережает автономию “инструментальную" - свободу в определении способов или графика работы. Вторым по значимости условием творческой деятельности отмечено "близкое по духу окружение» (63\%), что подчеркивает важность работы среди единомышленников, упоминавшуюся и в углубленных интервью. Интересно, что, опять же, "инструментальные» аспекты социальных взаимодействий, такие как возможность получения помощи от коллег, упоминаются значительно реже.

Результаты качественного этапа исследования позволили составить список проблем, с которыми сталкиваются в своей профессиональной деятельности творческие работники. Распределения в таблице 3 дают возможность судить о распространенности этих проблем.

Таблица З. Распределение ответов на вопрос “Сталкивались ли Вы со следующими проблемами в своей нынешней работе?", \% положительных ответов

\begin{tabular}{|l|c|}
\hline \multicolumn{1}{|c|}{ Варианты ответа } & $\%$ \\
\hline Отсутствие ресурсов для воплощения творческой идеи & 19 \\
\hline Высокий уровень конкуренции при трудоустройстве/поиске заказчика & 17 \\
\hline Учет запросов потребителя в ущерб собственному творческому замыслу & 17 \\
\hline Желания заказчика гораздо шире бюджета для реализации проекта & 15 \\
\hline Критика со стороны заказчика/режиссера, нежелание принять готовый результат & 13 \\
\hline Некомпетентность членов рабочей группы/труппы & 11 \\
\hline Недобросовестный заказчик (неоплата заказа) & 8 \\
\hline
\end{tabular}


Из списка проблем, связанных с осуществлением творческой деятельности, респонденты чаще всего упоминали отсутствие ресурсов для осуществления своих творческих идей и чуть реже - другие аспекты, ограничивающие свободу творчества в рамках упомянутой выше "рыночной" логики культурного производства [Peterson, Anand, 2004]: конкуренцию, ориентацию на потребителя. Однако доля отметивших эти проблемы - менее 20 \% опрошенных - свидетельствует, на наш взгляд, о том, что большинство творческих работников воспринимают ориентацию на рынок как естественные рамки для своей творческой деятельности, не чувствуя жесткого давления и конфликта "эстетического" и "экономического".

Другим объяснением малой доли отметивших проблемы адаптации творчества к требованиям рынка является то, что данные проблемы, скорее всего, сосредоточены на высших уровнях управления творческими организациями - именно руководители несут на себе “бремя" проблем взаимодействия с внешней средой, многие из которых не доходят до рядовых работников.

Таблица 4. Распределение ответов на вопрос “В какой степени, по Вашему мнению, размер Вашей зарплаты на этой работе зависит от следующих характеристик. Отметьте по шкале от 1 до 5, где „1“-совсем не зависит, а „5“-очень зависит”, \% по строке

\begin{tabular}{|c|c|c|c|}
\hline Утверждения & $\begin{array}{l}\text { Не зависит } \\
(\text { («1" и "2») }\end{array}$ & "3" & $\begin{array}{l}\text { Зависит } \\
(\text { (4» и «5») }\end{array}$ \\
\hline $\begin{array}{l}\text { Конечных результатов Вашей работы, } \\
\text { достижения конкретных показателей }\end{array}$ & 15 & 18 & 67 \\
\hline Объемов выполняемой Вами работы & 24 & 10 & 66 \\
\hline $\begin{array}{l}\text { Ваших формальных квалификационных показателей } \\
\text { (разряд, грейд, категория, степень, звание) }\end{array}$ & 27 & 13 & 60 \\
\hline Качества Вашей работы & 24 & 16 & 60 \\
\hline Результатов работы отдела, подразделения, труппы & 36 & 19 & 45 \\
\hline Результатов работы компании/учреждения в целом & 28 & 30 & 42 \\
\hline Ваших личных отношений с руководством & 46 & 22 & 32 \\
\hline
\end{tabular}

Распределения в таблице 4 представляют основные критерии, в соответствии с которыми, по мнению респондентов, определяется размер их денежного вознаграждения. Как видим, преобладают индивидуальные "меритократические» принципы вознаграждений, привязанные к объемам и результативности работы: их отметили более $60 \%$ респондентов. Значительно меньшая доля - менее половины - выбрали принципы вознаграждений, основанные на групповых результатах работы. Достаточно сильно дифференцирует творческих работников такой критерий, как личные отношения с руководителем. Треть респондентов указали на наличие такой зависимости, около половины - на ее отсутствие. Как показали более ранние исследования, система вознаграждений, основанная на субъективных оценках руководителя, может свидетельствовать о дисбалансе властных отношений в организации, социально-экономической зависимости подчиненного от руководителя, создающая условия для злоупотребления последним своей властью [Балабанова, Боровик, Деминская, 2018]. 
Таблица 5. Распределение ответов о справедливости системы вознаграждения на работе, $\%$ по строке

\begin{tabular}{|c|c|c|c|}
\hline $\begin{array}{c}\text { Уровень моего вознаграждения } \\
\text { на этой работе... }\end{array}$ & $\begin{array}{l}\text { Не согласны } \\
(« 1 " \text { и «2») }\end{array}$ & "3" & $\begin{array}{l}\text { Согласны } \\
\text { («4" и «5») }\end{array}$ \\
\hline $\begin{array}{l}\text {... справедлив по сравнению с уровнем } \\
\text { вознаграждения моих коллег }\end{array}$ & 18 & 17 & 65 \\
\hline ... адекватен результатам моей работы & 19 & 18 & 63 \\
\hline $\begin{array}{l}\text {... адекватен усилиям, которые я затрачиваю } \\
\text { на выполнение работы }\end{array}$ & 11 & 35 & 54 \\
\hline
\end{tabular}

Как видно из результатов в таблице 5, большинство респондентов оценивают уровень вознаграждения на своей нынешней работе как "справедливый", хотя при этом каждый пятый отметил несоответствие зарплаты результатам своей работы и уровню вознаграждения коллег, что говорит об актуальности проблемы социального сравнения, нарушения "дистрибутивной справедливости" для творческих работников, особенно актуальной в контексте высокой степени неравенства в творческих организациях, отмеченной в исследованиях [Conor, Gill, Taylor, 2015; Кулева, 2017]. Интересно, что более трети респондентов затруднились дать определенный ответ на вопрос о соответствии зарплаты затраченным усилиям, что, возможно, свидетельствует о “вторичности" данного параметра для определения уровня удовлетворенности работой.

Перейдем к рассмотрению мотивационных аспектов труда творческих работников. Как было отмечено выше, выраженность мотивации творческих работников операционализируется через их позитивные установки и надролевое поведение.

Таблица 6. Распределение ответов на вопрос «Насколько Вы удовлетворены различными характеристиками своей нынешней работы?", \% по строке

\begin{tabular}{|l|c|c|c|}
\hline \multicolumn{1}{|c|}{ Варианты ответа } & $\begin{array}{c}\text { Не удовлетворены; } \\
\text { скорее, не удовле- } \\
\text { творены (“1" и «2”) }\end{array}$ & “3” & $\begin{array}{c}\text { Удовлетворены; } \\
\text { скорее, } \\
\text { удовлетворены } \\
\text { (“4” и “5”) }\end{array}$ \\
\hline Отношения с коллегами и руководителем & 4 & 11 & 85 \\
\hline Режим работы, удобный рабочий график & 12 & 9 & 79 \\
\hline $\begin{array}{l}\text { Возможность иметь достаточно свободного } \\
\text { времени }\end{array}$ & 23 & 9 & 68 \\
\hline Сочетание работы и личной жизни & 14 & 21 & 66 \\
\hline $\begin{array}{l}\text { Условия труда, комфортность рабочего } \\
\text { места }\end{array}$ & 20 & 15 & 65 \\
\hline Стабильность, надежность рабочего места & 27 & 10 & 63 \\
\hline $\begin{array}{l}\text { Возможность проявить самостоятельность, } \\
\text { инициативу }\end{array}$ & 21 & 16 & 63 \\
\hline $\begin{array}{l}\text { Объем и темп работы, реалистичность } \\
\text { “дедлайнов" }\end{array}$ & 18 & 22 & 60 \\
\hline $\begin{array}{l}\text { Возможности обучения, профессионального } \\
\text { развития }\end{array}$ & 23 & 22 & 55 \\
\hline
\end{tabular}




\begin{tabular}{|l|c|c|c|}
\hline \multicolumn{1}{|c|}{ Варианты ответа } & $\begin{array}{l}\text { Не удовлетворены; } \\
\text { скорее, не удовле- } \\
\text { творены («1" и «2») }\end{array}$ & “3” & $\begin{array}{l}\text { Удовлетворены; } \\
\text { скорее, } \\
\text { удовлетворены } \\
\text { («4” и «5”) }\end{array}$ \\
\hline Перспективы карьерного роста & 32 & 26 & 42 \\
\hline Возможность влиять на людей & 25 & 23 & 52 \\
\hline Уровень зарплаты & 34 & 15 & 51 \\
\hline $\begin{array}{l}\text { Социальный пакет по месту работы } \\
\text { (страхование, оплата транспорта, сотовой } \\
\text { связи и т.п.) }\end{array}$ & 44 & 11 & 44 \\
\hline $\begin{array}{l}\text { Коммерческая окупаемость работы } \\
\text { (проекта, постановки) }\end{array}$ & 27 & 35 & 38 \\
\hline Значение а Кронбаха & \multicolumn{3}{|c|}{0,835} \\
\hline
\end{tabular}

Как видно из таблицы 6, творческие работники в наибольшей степени удовлетворены социальными отношениями на рабочем месте и теми аспектами своей работы, которые позволяют поддерживать баланс работы и жизни (режим, наличие свободного времени, условия труда).

Что же касается аспектов работы, по которым зафиксирована наибольшая доля неудовлетворенных, то это прежде всего социальный пакет по месту работы - им не удовлетворена почти половина опрошенных. Несколько парадоксально, что "социальный пакет" опережает даже уровень заработной платы - традиционного "лидера" в рейтингах неудовлетворенности работой среди россиян. В нашей выборке доля неудовлетворенных зарплатой составила чуть более трети опрошенных; почти столько же не удовлетворены перспективами карьерного роста.

Обратим внимание на высокую долю выбравших вариант “3», который можно интерпретировать как "затрудняюсь ответить", для параметра "Коммерческая окупаемость работы" (35\%). На наш взгляд, это подтверждает ранее выдвинутое предположение, что конфликт "творческой" и «предпринимательской" логик ощущается лишь относительно небольшой частью рядовых творческих работников.

Таблица 7. Распределение ответов о вовлеченности в работу, эмоциональном выгорании и намерениях покинуть организацию, \% по строке

\begin{tabular}{|l|c|c|c|}
\hline \multicolumn{1}{|c|}{ Утверждения } & $\begin{array}{c}\text { Не согласны } \\
\text { («1» и «2») }\end{array}$ & «3” & $\begin{array}{c}\text { Согласны } \\
\text { («4” и «5”) }\end{array}$ \\
\hline $\begin{array}{l}\text { Когда я просыпаюсь утром, мне хочется идти } \\
\text { на работу }\end{array}$ & 25 & 24 & 52 \\
\hline $\begin{array}{l}\text { К концу дня я совершенно истощен(а) физически } \\
\text { и психически }\end{array}$ & 49 & 28 & 23 \\
\hline $\begin{array}{l}\text { Планируете ли Вы в ближайшее время уйти } \\
\text { с данного места работы или стать самозанятым? }\end{array}$ & 41 & 32 & 27 \\
\hline
\end{tabular}

Распределения, представленные в таблице 7 , позволяют говорить, что половина творческих работников "вовлечены" в свою работу, испытывают от нее "драйв", положительные эмоции. Для четверти респондентов актуальна проблема эмоционального выгорания, связанная с эмоциональными перегрузками творческой 
работы. Примерно столько же $(27 \%)$ респондентов хотели бы уйти из организации, в которой работают сейчас.

Еще одним показателем «контекстуальной эффективности" [Wright, Staw, 1999; Harrison, Newman, Roth, 2006], отражающим уровень мотивации творческих работников, является реализация ими различных видов надролевого поведения (см. табл. 8).

Таблица 8. Распределение ответов на вопрос “Случалось ли Вам в течение последних 12 месяцев добровольно, по своей инициативе...?

Оцените по шкале от 1 до 5, где 1-ни разу, 5-часто"

\begin{tabular}{|c|c|c|c|}
\hline $\begin{array}{c}\text { Индекс } \\
\text { надролевого } \\
\text { поведения }\end{array}$ & Исходные переменные & $\begin{array}{c}\% \\
\text { положительных } \\
\text { ответов } \\
\text { (сумма } \\
\text { вариантов 4 и 5) }\end{array}$ & $\begin{array}{l}\text { Значение } \\
\text { а Кронбаха }\end{array}$ \\
\hline \multirow{4}{*}{$\begin{array}{l}\text { Просоциальное } \\
\text { поведение }\end{array}$} & $\begin{array}{l}\text { Помогать своим коллегам в выполнении } \\
\text { их работы }\end{array}$ & 66 & \multirow{4}{*}{0,892} \\
\hline & $\begin{array}{l}\text { Делиться опытом, знаниями, } \\
\text { профессиональной информацией с коллегами }\end{array}$ & 70 & \\
\hline & $\begin{array}{l}\text { Выражать одобрение, поддержку решениям } \\
\text { своего руководителя или вышестоящего } \\
\text { руководства }\end{array}$ & 66 & \\
\hline & $\begin{array}{l}\text { Помогать своему руководителю, предлагать } \\
\text { решение проблем, озвученных руководителем }\end{array}$ & 68 & \\
\hline \multirow{3}{*}{$\begin{array}{l}\text { Повышенные } \\
\text { трудовые } \\
\text { нагрузки }\end{array}$} & Работать в выходные дни & 72 & \multirow{3}{*}{0,867} \\
\hline & $\begin{array}{l}\text { Выполнять виды работ, не входящие в Ваши } \\
\text { прямые должностные обязанности }\end{array}$ & 69 & \\
\hline & $\begin{array}{l}\text { Задерживаться на работе сверх положенного } \\
\text { времени без оплаты }\end{array}$ & 70 & \\
\hline \multirow{3}{*}{$\begin{array}{l}\text { "Голос" } \\
\text { работника }\end{array}$} & $\begin{array}{l}\text { Привлекать внимание руководства } \\
\text { к допущенным ошибкам, проблемам }\end{array}$ & 52 & \multirow{3}{*}{0,777} \\
\hline & $\begin{array}{l}\text { Спорить с руководителем (тимлидом), } \\
\text { отстаивать собственное мнение по рабочим } \\
\text { вопросам }\end{array}$ & 50 & \\
\hline & $\begin{array}{l}\text { Высказывать руководству свои критические } \\
\text { замечания по рабочим вопросам }\end{array}$ & 42 & \\
\hline
\end{tabular}

Результаты анализа, представленные в таблице 8, показали, что надролевое поведение творческих работников проявляется в трех формах:

1) просоциальном поведении (помощь и поддержка коллегам и непосредственным руководителям);

2) сверхнормативных трудовых нагрузках;

3) «голосе», направленном на выявление проблем в организации и стремлении что-то изменить.

Как видно из доли положительных ответов, первые две формы надролевого поведения достаточно распространены среди творческих работников: около 
$70 \%$ респондентов отметили свое участие в них за год до проведения опроса. Значительно меньше (около половины опрошенных) выбрали "голос, бросающий вызов" (challenging voice) - поведение, нацеленное на изменение существующих практик, процессов в организации [Балабанова, Эфендиев, 2015]. Известно, что реализация такого поведения сопряжена с существенными рисками для работника (угроза репутации, возможность санкций со стороны руководства), поэтому для такого поведения работнику нужна достаточно серьезная мотивация и наличие ресурсов, уверенность в себе.

Рассмотрим, какие элементы организации рабочего процесса вносят наибольший вклад в удовлетворенность трудом творческих работников, их вовлеченность в работу, участие в различных видах надролевого поведения, а также эмоциональное выгорание и намерение покинуть организацию. Для ответа на этот вопрос была использована линейная регрессия с зависимыми переменными, характеризующими различные аспекты мотивации и социального благополучия респондентов. Поскольку представленные выше исходные переменные, характеризующие удовлетворенность работой и надролевое поведение, показали высокую степень внутренней согласованности (а Кронбаха на уровне 0,7 и выше), они были объединены в соответствующие индексы путем расчета средних значений по 5-балльной шкале. В качестве предикторов в модель были включены представленные выше аспекты организации рабочего процесса респондентов, а также контрольные переменные пола, возраста и проживания в Москве либо в регионах. Значимые коэффициенты для каждой из моделей представлены в таблице 9.

Таблица 9. Результаты регрессионного анализа с зависимыми переменными мотивации

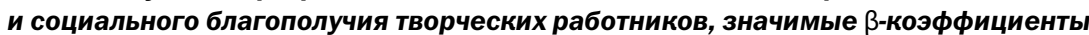

\begin{tabular}{|c|c|c|c|c|c|c|c|c|}
\hline \multirow{2}{*}{ 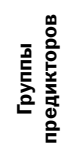 } & \multirow[b]{2}{*}{ Предикторы } & \multirow{2}{*}{ 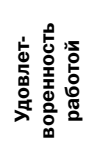 } & \multirow{2}{*}{ 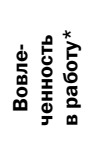 } & \multicolumn{3}{|c|}{ Надролевое поведение } & \multirow{2}{*}{ 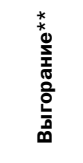 } & \multirow{2}{*}{ 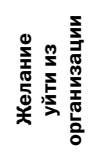 } \\
\hline & & & & 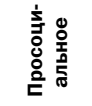 & 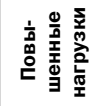 & $\begin{array}{l}\hat{\hat{̊}} \\
\text { 홇 }\end{array}$ & & \\
\hline $\begin{array}{l}\text { Конт- } \\
\text { роль- } \\
\text { ные }\end{array}$ & Возраст & & & ,106* & & & & \\
\hline \multirow{7}{*}{ 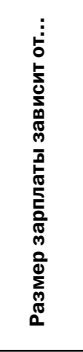 } & $\begin{array}{l}\text { Ваших формальных квалификационных } \\
\text { показателей }\end{array}$ & & & &, $370 * * *$ & & & \\
\hline & Объемов выполняемой Вами работы & & &, $206 * * *$ & &,$- 226 * * *$ & & \\
\hline & Качества Вашей работы & & & &, $113^{*}$ &,$- 163 *$ & & \\
\hline & $\begin{array}{l}\text { Конечных результатов Вашей работы, } \\
\text { достижения конкретных показателей }\end{array}$ &,$- 151 *$ & & & & & & \\
\hline & $\begin{array}{l}\text { Результатов работы отдела, подразделе- } \\
\text { ния, труппы }\end{array}$ &, $299 * * *$ & & & &, $234 * *$ & & \\
\hline & $\begin{array}{l}\text { Результатов работы компании/учрежде- } \\
\text { ния в целом }\end{array}$ & & &, $208 * * *$ & & & &, $281 * * *$ \\
\hline & Ваших личных отношений с руководством &,$- 152 *$ & & &, $225 * * *$ & & & \\
\hline \multirow{3}{*}{ 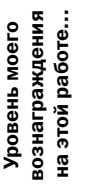 } & ...адекватен результатам моей работы & & &, $297 * * *$ & & & &,$- 281 * * *$ \\
\hline & $\begin{array}{l}\text {... адекватен усилиям, которые я затрачи- } \\
\text { ваю на выполнение работы }\end{array}$ & & & &,$- 161 * *$ & &,$- 142 *$ & \\
\hline & $\begin{array}{l}\text {... справедлив по сравнению с уровнем } \\
\text { вознаграждения моих коллег }\end{array}$ & &, $224 * * *$ &, $278 * * *$ & &,$- 355 * * *$ & & \\
\hline
\end{tabular}




\begin{tabular}{|c|c|c|c|c|c|c|c|c|}
\hline \multirow{2}{*}{ 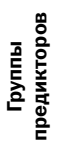 } & \multirow[b]{2}{*}{ Предикторы } & \multirow{2}{*}{ 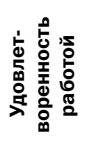 } & \multirow{2}{*}{ 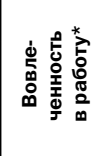 } & \multicolumn{3}{|c|}{ Надролевое поведение } & \multirow{2}{*}{ 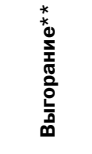 } & \multirow{2}{*}{ 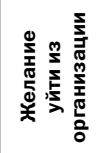 } \\
\hline & & & & 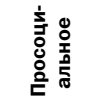 & 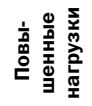 & 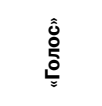 & & \\
\hline \multirow{4}{*}{ 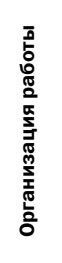 } & $\begin{array}{l}\text { Возможность гибкого графика (работа } \\
\text { на дому) }\end{array}$ & & &,$- 106 *$ & &, $202 * * *$ & ,123* & \\
\hline & $\begin{array}{l}\text { Внутренняя система повышения квалифи- } \\
\text { кации (онлайн-курсы, коучинг, творческие } \\
\text { встречи, тренинги и др.) }\end{array}$ & &,$- 180 * *$ & & & & & \\
\hline & $\begin{array}{l}\text { Были ли у Вас за последний год конфлик- } \\
\text { ты с коллегами? }(1=\text { "да") }\end{array}$ & &,$- 136 *$ & & & & & \\
\hline & $\begin{array}{l}\text { Сколько примерно часов Вы работали } \\
\text { за последнюю полную рабочую неделю? }\end{array}$ & & & & & & ,116* &, $170 * *$ \\
\hline \multirow{5}{*}{ 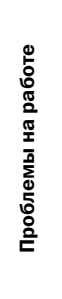 } & $\begin{array}{l}\text { Недобросовестный заказчик (неоплата } \\
\text { заказа) }\end{array}$ & & & & & & &, $180 * *$ \\
\hline & $\begin{array}{l}\text { Некомпетентность членов рабочей } \\
\text { группы }\end{array}$ & & & &,$- 105 *$ &,$- 217 * * *$ & & \\
\hline & $\begin{array}{l}\text { Критика со стороны заказчика/режиссе- } \\
\text { ра, нежелание принять результат }\end{array}$ & & & & & ,163** &,$- 200 * *$ &,$- 252 * * *$ \\
\hline & $\begin{array}{l}\text { Учет запросов потребителя в ущерб соб- } \\
\text { ственному творческому замыслу }\end{array}$ & & & ,105* &,$- 114 *$ & & & \\
\hline & $\begin{array}{l}\text { Желания заказчика гораздо шире бюд- } \\
\text { жета для реализации проекта }\end{array}$ & &,$- 264 * * *$ &,$- 160 * *$ & & & & \\
\hline & Скорректированный $\mathrm{R}^{2}$ & ,064 & 134 & ,330 & ,224 & 284 &, 084 & ,236 \\
\hline
\end{tabular}

* Формулировка вопроса: “Когда я просыпаюсь утром, мне хочется идти на работу”.

** Формулировка вопроса: “К концу дня я совершенно истощен(а) физически и психически».

Результаты регрессионного анализа, представленные в таблице 9, позволяют сделать общий вывод, что для мотивации творческих работников важны факторы материального вознаграждения и организации работы.

Так, мы видим, что удовлетворенность работой выше в условиях оплаты по результатам групповой работы. Это подтверждает значимость групповых взаимодействий для творческих работников, отмеченная как в имеющихся исследованиях, так и в результатах наших углубленных интервью. Напротив, привязка оплаты как к индивидуальной результативности, так и к личным отношениям с руководителем (влекущая за собой субъективизм, произвольность в оценивании, зависимость работника и злоупотребление руководителями своей властью), снижает удовлетворенность работой.

Вовлеченность в работу предсказывается воспринимаемой справедливостью оплаты труда по сравнению с коллегами, что также показывает высокую значимость факторов материального вознаграждения для мотивации творческих работников. В свою очередь, снижает вовлеченность наличие конфликтов с коллегами, нереалистичные желания заказчиков и, что интересно, наличие в организациях системы повышения квалификации. Можно предположить, что "формальные» обучающие мероприятия плохо воспринимаются творческими работниками, приводя к лишней нагрузке и не обеспечивая развития действительно ценных навыков и качеств.

Для демонстрации просоциального поведения наиболее значимыми оказались воспринимаемая справедливость вознаграждений, привязка вознаграждений к объемам работы и результатам деятельности организации в целом, а также стар- 
ший возраст респондентов (это единственная значимая контрольная переменная в тестируемых моделях). Интересно, что снижает готовность помогать коллегам и руководителям возможность удаленной работы, разобщающая сотрудников (подчеркнем, что опрос проходил в начале 2020 г., то есть до того момента, когда дистанционная занятость оказалась повсеместной вынужденной необходимостью). Можно предположить, что именно для творческой деятельности работа в коллективе, наличие живого контакта особенно важны.

Ведущими факторами, заставляющими творческих работников «перерабатывать", выходить за пределы своих рабочих обязанностей, оказались зависимость вознаграждения от формальных квалификационных показателей и от личных отношений с руководителем. Вероятно, в условиях организации работы, когда ценится "лояльность", именно демонстрация повышенных усилий, готовность работать в режиме авралов становится средством обретения расположения руководителя.

Интересен набор факторов, мотивирующих респондентов к выражению "голоса" - высказыванию критических замечаний, направленных на улучшение в организации или подразделении. Усиливают мотивацию “голоса" зависимость заработной платы от групповых результатов и воспринимаемая несправедливость распределения вознаграждений, возможность удаленной работы, а также критические замечания со стороны заказчиков. В том же случае, если респонденты сталкиваются с проблемой профессиональной некомпетентности своих коллег, их готовность к высказыванию критических предложений и замечаний снижается.

Уровень эмоционального выгорания респондентов выше в условиях большого объема работы, что вполне ожидаемо, при воспринимаемой неадекватности уровня вознаграждений затраченным усилиям, а также в условиях удаленной занятости (факт, позже выявленный во многих массовых опросах в период пандемии).

Что же касается желания работников покинуть организацию, то мы опять видим ведущую роль "зарплатных" факторов - неадекватность зарплаты результатам работы, "растворение" индивидуального вклада в результатах работы организации в целом. Подталкивают к уходу из организации также большая продолжительность рабочей недели и проблемы с недобросовестными заказчиками. При этом критика со стороны режиссера/заказчика не повышает, а снижает уровень эмоционального выгорания и желания уйти из организации, что можно объяснить тем фактом, что критика - естественный, неотьемлемый элемент творческого процесса.

\section{Заключение}

Исследования, посвященные труду работников творческих профессий в условиях организационных границ, традиционно акцентируют внимание на двойственной природе этой профессиональной деятельности. Социально-трудовые практики в творческих профессиях и отраслях должны одновременно ориентироваться на возможность реализации творческого потенциала и соответствие критериям экономической эффективности. Большое количество работ [Eikhof, Haunschild, 2006; Gotsi et al., 2010] рассматривают эту двойственность как источник конфликта, предъявляющий к работникам противоположные по своему характеру требования, размывающие их профессиональную идентичность, повышающие неудовлетворенность и провоцирующие выгорание. 
Результаты нашего исследования с опорой на стратегию "смешивания методов" позволили несколько скорректировать понимание специфики творческого труда в российских организациях. Данные качественного этапа дали возможность описать характер и условия формирования двойственной (мета-)идентичности творческих работников, выявить их нормативные приоритеты, ожидания от системы управления. Лейтмотивом ответов информантов было подчеркивание важности творческой самореализации, автономии, независимости, "расширения границ" как условий, необходимых для их профессиональной деятельности.

Стандартизованный опрос, с одной стороны, подтвердил сильную выраженность у респондентов нормативных ожиданий, связанных со спецификой творческого труда. Особенно требовательны представители творческих профессий к таким условиям своей деятельности, как возможность самостоятельно определять цели своей работы и работать среди "близких по духу" единомышленников. Получили подтверждение и более ранние наблюдения о высокой значимости групповых взаимодействий, командной работы для творческой деятельности. Важно отметить, что при этом социально-демографические или индивидуально-личностные особенности респондентов оказались незначимыми в формировании их установок и поведения.

С другой стороны, мы выявили, что ведущую роль в формировании таких мотивационных составляющих, как удовлетворенность трудом, вовлеченность в работу, надролевое поведение, желание остаться в организации и отсутствие эмоционального выгорания, играют организационно-управленческие практики, связанные с удовлетворением материальных потребностей работников, критериями вознаграждений, воспринимаемой справедливостью в оплате труда. По нашему мнению, это позволяет сделать вывод, что двойственная идентичность творческих работников, “эстетическая" и "рыночная" логики в творческой деятельности, отмеченные в ряде предыдущих исследований [Thornton, Jones, Kury 2005; Скотт, 2007], не противоречат, а дополняют друг друга. Базовые условия мотивационного процесса, такие как комфортные условия труда, социальное сравнение, воспринимаемая адекватность вознаграждений усилиям и результатам, которые часто отходят на второй план в дискуссиях об уникальности творческого труда, столь же актуальны для творческих работников, как и для представителей других видов профессиональной деятельности. Таким образом, есть основания говорить о наличии определенного противоречия между нормативным дискурсом о специфике творческого труда и реальными практиками социально-трудовой деятельности творческих работников в организационном контексте.

Ограничением данной работы является невероятностный характер выборки и относительно небольшой ее размер, не позволяющий в полной мере отразить гетерогенность объекта исследования, выявить различия специфики трудовой мотивации внутри творческих отраслей и профессий. Наиболее перспективными направлениями для дальнейших исследований на базе полученных результатов представляются:

- 1) анализ специфики внедрения современных технологий, степень их влияния на организацию труда и управления в творческих организациях;

- 2) анализ проектных форм деятельности творческих работников, специфики творческой работы в командах, в том числе виртуальных. 


\section{Список литературы (References)}

Абрамов Р.Н. Практический опыт рекрутирования целевой выборки с помощью социальных сетей: кейс опроса о ностальгии по советскому // Социология: методология, методы, математическое моделирование (4М). 2019. № 48. С. 83-112. Abramov R. N. (2019) The Practical Experience of Recruiting the Target Sample Using Social Networks: The Case of the Survey on the Nostalgia for the Soviet Past. Sociology: Methodology, Methods, Mathematical Modeling (4M). No. 48. P. 83-112. (In Russ.)

Адорно Т., Хоркхаймер Т. Диалектика Просвещения. Философские фрагменты. М.: Медиум, 1997.

Adorno T., Horkkhajmer T. Dialectics of Enlightenment. Philosophical fragments. Moscow: Medium, 1997. (In Russ.)

Балабанова Е. С., Баранова Д.А., Деминская В.Э. Надролевое поведение работника: проявления, предпосылки и последствия // Вестник СПбГУ. Серия 12. Социология. 2017. № 2. С. 185-200. https://doi.org/10.21638/11701/ spbu12.2017.204.

Balabanova E.S, Baranova D. A., Deminskaya V.E. (2017) Employee Extra-Role Behavior: Manifestations, Antecedents and Consequences. Vestnik of Saint Petersburg University. Sociology. No. 2. P. 185-200. https://doi.org/10.21638/11701/ spbu12.2017.204. (In Russ.)

Балабанова Е. С., Боровик М. Э., Деминская В. Э. “Враждебное» поведение руководителя: проявления, предпосылки и последствия // Российский журнал менеджмента. 2018. Т. 16. № 3. С. 309-336.

Balabanova E. S., Borovik M.E., Deminskaya V.E. (2018) Abusive Supervision: Manifestations, Antecedents, and Consequences. Russian Management Journal. No. 3. P. 309-336. https://doi.org/10.21638/spbu18.2018.301. (In Russ.)

Балабанова Е.С., Эфендиев А.Г. «Голос работника в российских бизнесорганизациях: концептуализация и результаты эмпирического анализа // Мир России: Социология, этнология. 2015. Т. 24. № 3. С. 61-87.

Balabanova E., Edendiev A. (2015) The Voice of Employees in Russian Business Organizations: Conceptualization and Empirical Analysis. Universe of Russia. No. 3. P. 61-87. (In Russ.)

Бурдье П. Поле политики, поле социальных наук, поле журналистики // Социоанализ Пьера Бурдье. Альманах Ин-та социологии РАН. М.: Ин-т экспериментальной социологии; СПб.: Алетейя, 2001.

Bourdieu P. (2001) Field of Politics, Field of Social Sciences, Field of Journalism. In: Socioanalysis of Pierre Bourdieu. Almanac of the Institute of Sociology of the Russian Academy of Sciences. Moscow: Institute of Experimental Sociology; St. Petersburg: Aleteya. (In Russ.)

Квале С. Исследовательское интервью. М.: Смысл, 2003.

Kvale S. Interviews: An Introduction to Qualitative Research Interviewing. Moscow: Smysl, 2003. (In Russ.) 
Кулева М.И. Трансформация творческой занятости в современной России: на примере сотрудников негосударственных арт-центров Москвы // Мониторинг общественного мнения: экономические и социальные перемены. 2017. № 2. С. 50-62. https://doi.org/10.14515/monitoring.2017.2.03.

Kuleva M. I. (2017) Transformation of Creative Employment: A Case Study of Moscow Non-Governmental Art Centers. Monitoring of Public Opinion: Economic and Social Changes Journal. No. 2. P. 50-62. https://doi.org/10.14515/monitoring.2017.2.03. (In Russ.)

Магидович М.Л. Профессиональная идентичность художника / Журнал социологии и социальной антропологии. 2004. № 3. С. 139-152.

Magidovich M. (2004) The Professional Identity of Artists. The Journal of Sociology and Social Anthropology. No. 3. P. 139-152. (In Russ.)

Матецкая М. Творческие индустрии: перспективы социально-экономической трансформации // Вестник Института экономики Российской академии наук. 2011. № 3. С. $195-206$.

Mateckaya M. (2011) Creative Industry: Perspectives on the Socio-Economic Transformation. Bulletin of the Institute of Economics of the Russian Academy of Sciences. No. 3. P. 195-206. (In Russ.)

Панов Л.Г. Политическое поле и институциональная логика // Политическая наука. 2018. № 2. С. $136-150$.

Panov L. G. (2018) The Political Field and Institutional Logics. Political Science (RU). No. 2. P. $136-150$. (In Russ.)

Романов П., Ярская-Смирнова Е. Социология профессий: аналитические перспективы и методология исследований. М.: О00 «Вариант». 2015.

Romanov P., larskaia-Smirnova E. (2015) Sociology of Professions: Analytical Prospects and Research Methodology. Moscow: 000 «Variant». (In Russ.)

Савинская О.Б., Истомина А. Г., Ларкина Т. Ю., Круглова К. Д. Концептуальные представления о стратегиях "смешивания методов" (mixed methods research): этапы развития и современные дискуссии // Социологические исследования. 2016. № 8. C. $21-29$.

Savinskaya O. B., Istomina A. G., Larkina T. Yu., Kruglova K. D. (2016) Conceptual Ideas of Mixed Methods Research: Stages of Development and Current Debates. Sociological Studies. No. 8. P. 21-29. (In Russ.)

Скотт В.Р. Конкурирующие логики в здравоохранении: профессиональная, государственная и менеджериальная // Экономическая социология. 2007. № 1. С. 27-44. Scott R. W. (2007) Competing Logics in Health Care: Professional, State, and Managerial. Economic Sociology. No. 1. P. 27-44. (In Russ.)

Флорида Р. Креативный класс. Люди, которые создают будущее. М.: Манн, Иванов и Фербер, 2016.

Florida R. (2016) The Rise of the Creative Class. And How It's Transforming Work, Leisure and Everyday Life. Moscow: Mann, Ivanov and Ferber. (In Russ.) 
Amabile T. M., Pratt M. G. (2016) The Dynamic Componential Model of Creativity and Innovation in Organizations: Making Progress, Making Meaning. Research in Organizational Behavior. Vol. 36. P. 157-183. https://doi.org/10.1016/ j.riob.2016.10.001.

Boltanski L., Chiapello E. (2005) The New Spirit of Capitalism. London: Verso.

Cerasoli C. P., Nicklin J. M., Ford M. T. (2014) Intrinsic Motivation and Extrinsic Incentives Jointly Predict Performance: A 40-Year Meta-Analysis. Psychological Bulletin. Vol. 140. No. 4. P. 980-1008. https://doi.org/10.1037/a0035661.

Conor B., Gill R., Taylor S. (2015) Gender and Creative Labour. The Sociological Review. Vol. 63. No. 1. P. 1-22. https://doi.org/10.1111/1467-954X.12237.

Cowen T. (2000) In Praise of Commercial Culture. Cambridge, Mass.; London: Harward University Press.

Deci E. L., Olafsen A. H., Ryan R. M. (2017) Self-Determination Theory in Work Organizations: The State of a Science. Annual Review of Organizational Psychology and. Organizational Behavior. No. 4. P. 19-43. https://doi.org/10.1146/annurev-orgpsych032516-113108.

Durand R., Jourdan J. (2012) Jules or Jim: Alternative Conformity to Minority Logics. Academy of Management Journal. Vol. 55. No. 6. P. 1295-1315. https://doi.org/ 10.5465/amj.2011.0345.

Eikhof D. R., Haunschild A. (2006) Lifestyle meets market: Bohemian entrepreneurs in creative industries. Creativity and Innovation Management. Vol. 15. No. 3. P. 234-241. https://doi.org/10.1111/j.1467-8691.2006.00392.

Ensor J., Cottam A., Band C. (2001) Fostering Knowledge Management Through the Creative Work Environment: A Portable Model From the Advertising Industry. Journal of Information Science. Vol. 27. No. 3. P. 147-155. https://doi.org/10.1177/ 016555150102700304.

Gotsi M., Andriopoulos C., Lewis M., Ingram A. E. (2010) Managing Creatives: Paradoxical Approaches to Identity Regulation. Human Relations. Vol. 63. No. 3. P. 781-805. https://doi.org/10.1177/0018726709342929.

Hackman J. R., Oldham G. R. (1980) The Design of Work. Reading, MA: Addison-Wesley. Harrison D. A., Newman D. A., Roth P. L. (2006) How Important Are Job Attitudes? Metaanalytic Comparisons of Integrative Behavioral Outcomes and Time Sequences. Academy of Management Journal. Vol. 49. No. 2. P. 305-325. https://doi.org/10.5465/ AMJ.2006.20786077.

Hesmondhalgh D. (2002) The Cultural Industries: SAGE Publications.

Kahn W. A. (1990) Psychological Conditions of Personal Engagement and Disengagement at Work. Academy of Management Journal. Vol. 33. No. 4. P. 692-724. https:// doi.org/10.5465/256287. 
Peltoniemi M. (2014) Cultural Industries: Product-Market Characteristics, Management Challenges and Industry Dynamics. International Journal of Management Reviews. Vol. 17. No. 1. P. 41-68. https://doi.org/10.1111/ijmr.12036.

Peterson R. A., Anand N. (2004) The Production of Culture perspective. Annual Review of Sociology. Vol. 30. P. 311-334. https://doi.org/10.1146/annurev. soc.30.012703.110557.

Rich B. L., LePine J.A., Crawford E. R. (2010) Job Engagement: Antecedents and Effects on Job Performance. Academy of Management Journal. Vol. 53. No. 3. P. 617-635. https://doi.org/10.5465/AMJ.2010.51468988.

Schaufeli W. B., Salanova M., Gonzalez-Roma V., Bakker A. B. (2002) The Measurement of Engagement and Burnout: A Two Sample Confirmatory Factor Analytic Approach. Journal of Happiness Studies. Vol. 3. P. 71-92. https:/ /doi.org/10.1023/A:1015630930326.

Thornton P., Jones C., Kury K. (2005) Institutional Logics and Institutional Change in Organizations: Transformation in Accounting, Architecture, and Publishing. Research in the Sociology of Organizations. Vol. 23. P. 125-170. https://doi.org/10.1016/ s0733-558X(05)23004-5.

Throsby D. (2001) Defining the Artistic Workforce: The Australian Experience. Poetics. Vol. 28. No. 4. P. 255-271. https://doi.org/10.1016/S0304-422X(01)80003-6.

Tschang T. (2007) Balancing the Tensions Between Rationalization and Creativity in the Video Games Industry. Organization Science. Vol. 18. No. 6. P. 885-1027. https:// doi.org/10.1287/orsc.1070.0299.

Wright T. A., Staw B. M. (1999) Affect and Favorable Work Outcomes: Two Longitudinal Tests of the Happy — Productive Worker Thesis. Journal of Organizational Behavior. Vol. 20. P. 1-23. 